\title{
Synergistic Effect between Electrochemical and Ultrasound Treatments for Microcystin-LR using BDD electrodes
}

\author{
Ying Gao ${ }^{a}$, Wanlin Zhang ${ }^{b}$, Wei Wu ${ }^{\mathrm{c},}{ }^{*}$, Hong Yang ${ }^{\mathrm{d}}$, Li Lie, Weiwei Wang ${ }^{\mathrm{f}}$ \\ Key Laboratory of Environmental Medicine and Engineering, Ministry of Education, School of \\ Public Health, Southeast University, Nanjing, 210009, China \\ a3236027533@qq.com, b1292665976@qq.com, c101005800@seu.edu.cn, \\ dyanghongr@seu.edu.cn, e1404157708@qq.com, f1715556404@qq.com.
}

Keywords: Son electrochemical, Electrolysis, Ultrasound, Microcystin-LR, BDD electrodes.

\begin{abstract}
Sonoelectrochemical degradation (US-EC), a relatively new AOPs, is a technique that combined sonication (US) and electrolysis (EC) without the need for additional chemicals for the procedure. Microcystin-LR (MC-LR), as the most toxic and most widespread algal toxin, are threat to human health. Until now US-EC technique have never been applied to MC-LR decomposition. The aim of this paper is to study the effect of MC-LR degradation of US-EC, optimize the sonochemical and electrochemical parameters involved in MC-LR decomposition. US-EC degradation of MC-LR was better than US or EC alone in terms of time and degradation efficiency. The degradation rate of MC-LR was up to $93 \%$ applying US $(20 \mathrm{kHz}, 15 \mathrm{~W})$ to the EC $\left(6 \mathrm{~mA} \mathrm{~cm}^{-2}\right)$ for $5 \mathrm{~min}$, and the residual concentration of MC-LR in the water was less than $1 \mu \mathrm{g} \mathrm{L}^{-1}$ (the limits set by WHO). With processing time is extended to 10 minutes, the degradation rate was reached $99 \%$.
\end{abstract}

\section{Introduction}

Microcystins (MCs), a kind of by-products of cyanobacteria, are important contaminants of aquatic ecosystems and pose a threat to human health. MCs are a family of cyclic heptapeptides with over 90 structural variants, and MC-LR is the most toxic and most widespread variant [1]. MC-LR are potent toxins that many researchers have reported that can cause multiple effects on human health. Toxicological studies have shown that the main target organs of MC-LR is liver[2], besides, it can also cause the gastrointestinal tract, kidney and pancreas, nervous system, reproductive system damage[3-5]. MC-LR has also been proved to be a potential human carcinogen[6-8]. The WHO recommends its exposure limit of MC-LR in drinking water to $1.0 \mu \mathrm{g} \mathrm{L-1[9].}$

The structure of MC-LR is so stable that the conventional water treatment processes can poorly remove it from water[10,11].The sonoelectrochemical oxidation technology(US-EC), a relatively new advanced oxidation technology (AOPs), which has the advantage of not requiring additional chemicals in the treatment and use of electricity as a main component[12]. Compared with other AOPs, US-EC is a kind of environmentally friendly technology with no need for additional chemicals. Although sometimes required the addition of salts to maintain electrical conductivity in laboratory experiments, however it's not required in practical application because of the high conductivity of natural wastewaters. The method is based on the synergetic effect of ultrasonication (US) and electrolysis (EC), which generate highly oxidizing species such as hydroxyl radicals.

The main disadvantages of EC is the polarization and passivation of electrodes due to poor mass transfer, which results in diminishing of the process efficiency. Furthermore, using US alone degradation of organic matter are kind of higher energy-consuming. US combined with the EC technique eliminates electrode contamination because of the continuous mechanical cleaning effect generated by the cavitation effect near to the electrode surface ${ }^{[13]}$. In recent years, US-EC were applied to the degradation of a range of different compounds such as dyes, organics, pesticides and pharmaceuticals[14-17].

The aim of this study is to investigate US-EC decomposition of MC-LR using recently developed BDD electrodes, which were proved to be effective in the degradation of organic pollutant ${ }^{[18]}$. In this 
work, we report for the first time a synergetic effect of electrochemical and sonochemical parameters in the US-EC decomposition of MC-LR.

\section{Experimental methods}

\subsection{Electrochemical experiments}

The MC-LR $(\geq 95 \%)$ was purchased from Enzo, USA. The initial concentration of MC-LR was 10 $\mu \mathrm{g} \mathrm{L} \mathrm{L}^{-1}$. The volume of the MC-LR solution was $100 \mathrm{~mL}$. and the experiments were performed in a glass cell with a two electrode configuration, During the EC and US-EC tests $0.05 \mathrm{M}$ of $\mathrm{Na}_{2} \mathrm{SO}_{4}$ used as supporting electrolyte. Samples were withdrawn for analysis at different time intervals.

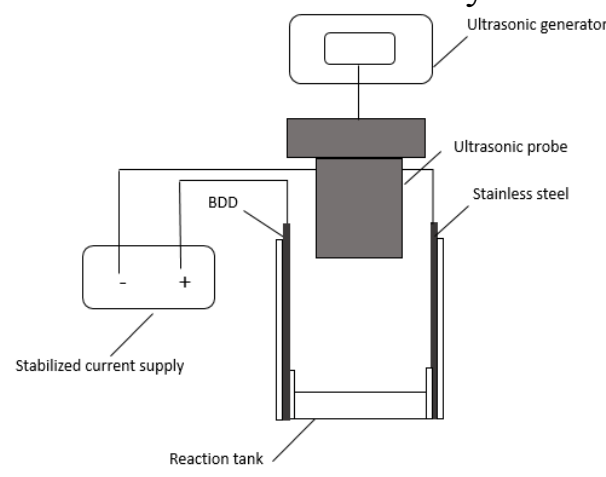

Fig. 1 experimental device

Electrochemical degradation test was carried out using a BDD (boron-doped diamond) as the anode and the cathode plate electrode was made of stainless steel. The effective area of the electrode was about $29 \mathrm{~cm}^{2}$ and the gap between the electrodes of $3.4 \mathrm{~cm}$. The electrodes used were connected to a stabilized current supply, and the applied current density were 2, $6,10 \mathrm{~mA} \mathrm{~cm}^{-2}$.

Ultrasonic experiments were carried out at $20 \mathrm{kHz}$ and three power $(5,10,15 \mathrm{~W})$. The ultrasound was introduced directly into the sample solution through an immersible probe that emits the sound of vibration into the solution.

Sonoelectrochemical degradation was carried out by an ultrasound horn immersed in solution. The other conditions were the same as those in the ultrasound and electrochemical processes.

\subsection{High-Performance Liquid Chromatography}

The quantitative analysis of EC, US and US-EC exposed MC-LR final samples were done using HPLC (1100, Agilent, USA) equipped with a UV (G1315B DAD) detector. The mobile phase consisted of $53 \% \mathrm{CH}_{3} \mathrm{OH}$ and $47 \%$ water with $0.05 \%$ TFA at a flow rate of $1 \mathrm{~mL} \mathrm{~min}^{-1}$. The injection volume was $20 \mu \mathrm{L}$. Chromatograms were analyzed and integrated at $238 \mathrm{~nm}$. Figure 2 shows MCLR chromatograms.

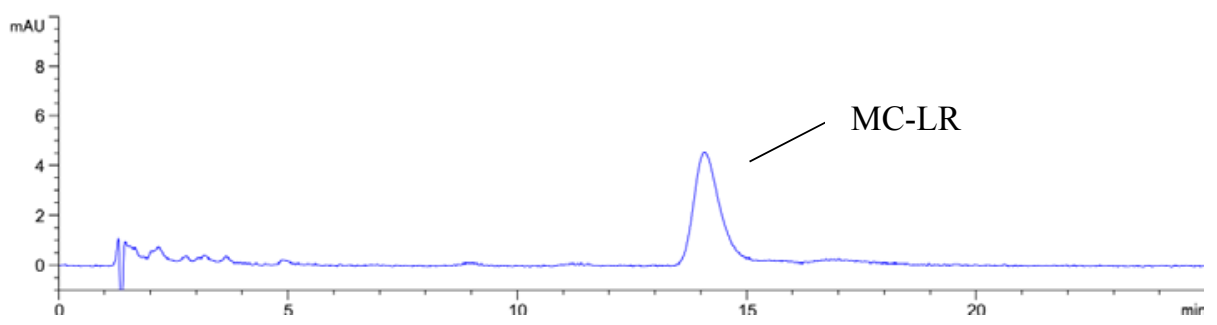

Fig. 2 Chromatograms of MC-LR 


\section{Results and discussion}

\subsection{Electrochemical and sonochemical degradation of MC-LR}

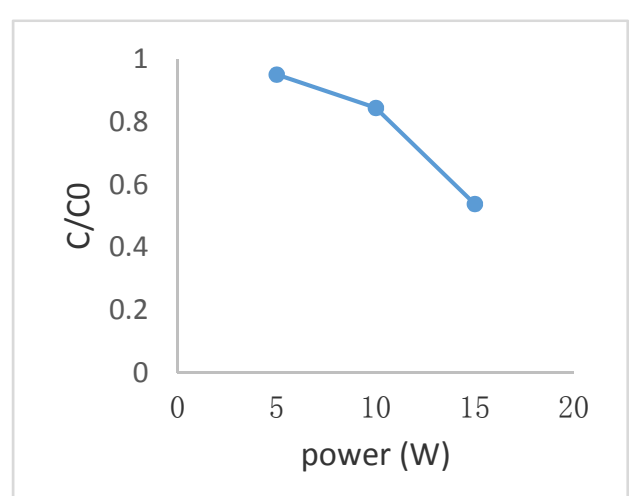

Fig. 3. Variation of MC-LR versus the ultrasonic power.

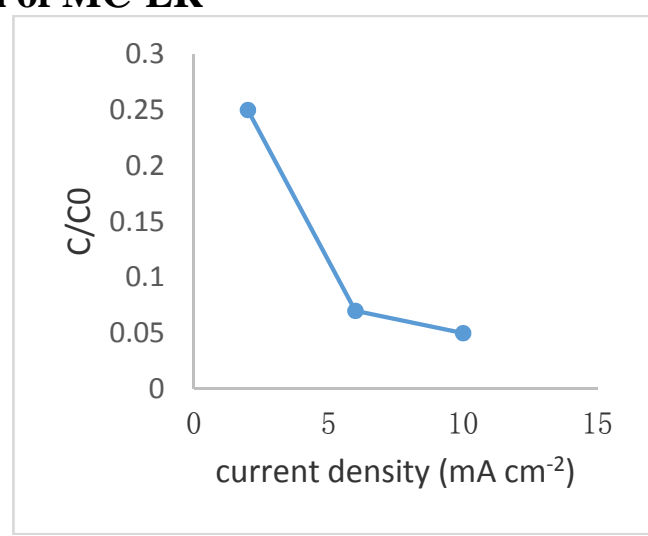

Fig. 4. Variation of MC-LR versus the current density

The effect of the ultrasonic power on the removal efficiency of MC-LR was evaluated at 5, 10 and $15 \mathrm{~W}$ by applied sonication alone for a treatment period of $10 \mathrm{~min}$. Fig. 3 shows removal efficiency of MC-LR changes as a function of the ultrasonic power imposed. The maximum compound removal was about $54 \%$ for a treatment period of $10 \mathrm{~min}$ of sonication at $15 \mathrm{~W}$. A lower removal efficiency of $5 \%$ and $85 \%$ was respectively obtained for the ultrasonic power of $5 \mathrm{~W}$ and $10 \mathrm{~W}$. Thokchom[19] report that MC-LR degradation using ultrasonic frequencies of $20 \mathrm{kHz}$ (rated output power $100 \mathrm{~W}$ ) after 10 min irradiation was about $40 \%$, and the results of the research also consider the removal efficiency of MC-LR increased with the ultrasonic frequency imposed. High-frequency ultrasound is usually used to remove contaminant in the water because of the generation of increased amounts of hydroxyl radicals. However, several technical defects cast doubt upon the equitability and efficiency of high-frequency reactors. First, high-frequency ultrasound require more power than that of lowfrequency. The physical effects are another important consideration for selecting low-frequency ultrasound. The share, turbulence and acoustic streaming dominate low-frequency operations, which provide beneficial effects, particularly for integrated operation with other AOPs[20]. Hence, lowfrequency ultrasoound was used in this work.

In contrast to sonication the use of electrolysis alone achieved a $95 \%$ reduction in MC-LR in the same time period (Fig. 4). For this reason it was considered that $6 \mathrm{~mA} \mathrm{~cm}^{-2}$ was the best current to employ because $10 \mathrm{~mA} \mathrm{~cm}^{-2}$ provided only a slight improvement in removal efficiency. To prove the suggestion sonoelectrochemical experiments were conducted at $20 \mathrm{kHz}(15 \mathrm{~W})$ at applied currents of 2,6 and $10 \mathrm{~mA} \mathrm{~cm}^{-2}$.

\subsection{Sonoelectrochemical degradation experiments}

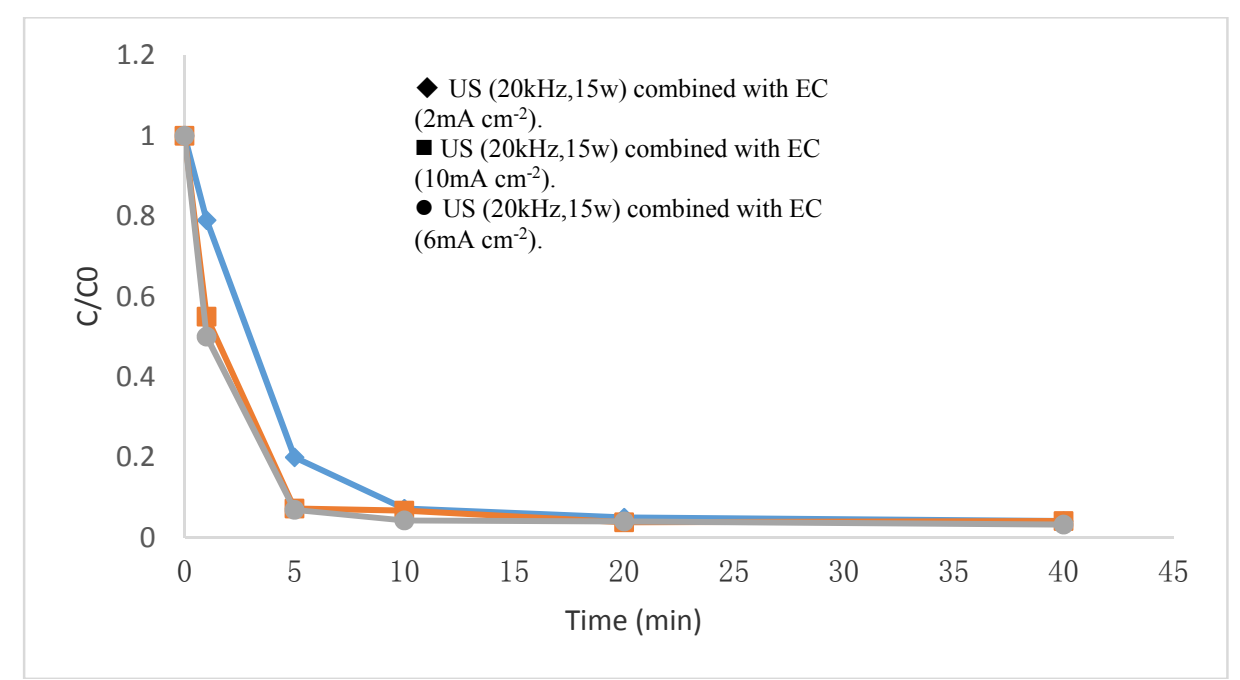

Fig. 5 Effect of current density on MC-LR degradation of US-EC. 


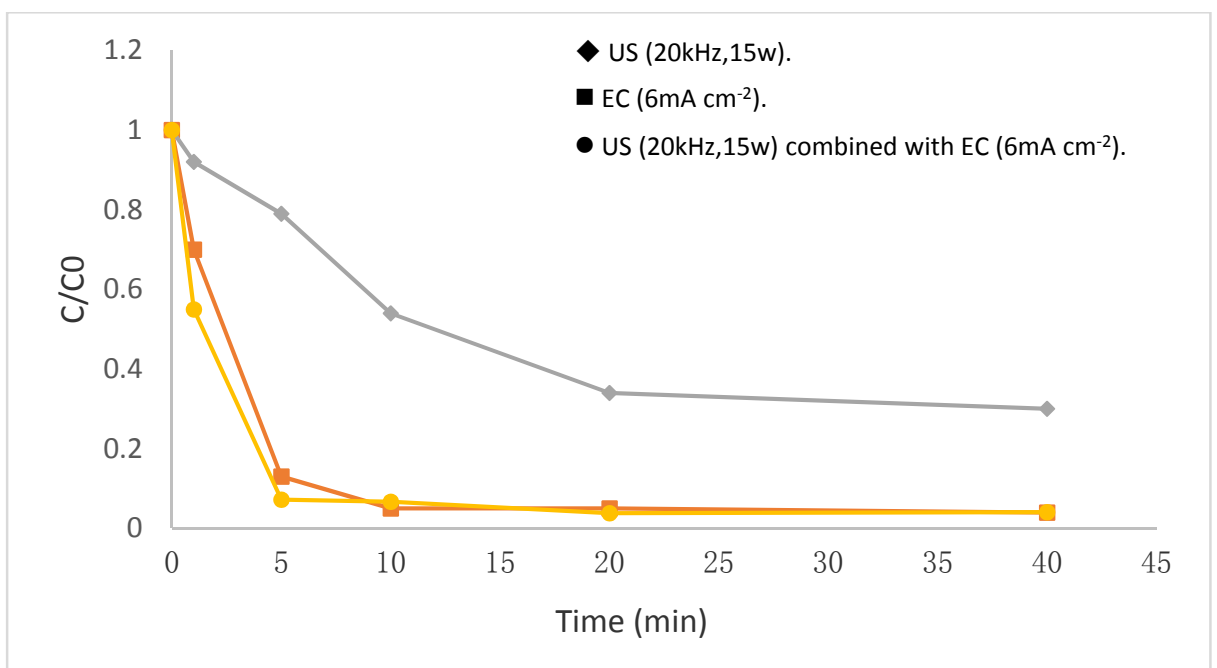

Fig. 6 MC-LR degradation efficiency of US, EC and US-EC.

US-EC were performed on the degradation of MC-LR applying currents density of 2, 6 and $10 \mathrm{~mA}$ $\mathrm{cm}^{-2}$ and irradiating solution with $20 \mathrm{kHz}(15 \mathrm{~W})$. The degradation efficiencies in these processes are shown in Fig. 4. The degradation effects of the US, EC and US-EC was also compared (Fig.5.).The combined use of sonication $(20 \mathrm{kHz}, 15 \mathrm{~W})$ and electrolysis $\left(6 \mathrm{~mA} \mathrm{~cm}^{-2}\right)$ increased the degradation efficiency over electrolysis alone in the first $5 \mathrm{~min}$, the removal rate was reached $45 \%, 93 \%$ respectively after $1,5 \mathrm{~min}$ under $\mathrm{US}(20 \mathrm{kHz}, 15 \mathrm{~W})$ combined with EC $\left(6 \mathrm{~mA} \mathrm{~cm}^{-2}\right)$, and $30 \%, 87 \%$ at the same time be applied by EC $\left(6 \mathrm{~mA} \mathrm{~cm}^{-2}\right)$, after $10 \mathrm{~min}$, the degradation rate was both reach $99 \%$. However, after $5 \mathrm{~min}$ under US $(20 \mathrm{kHz}, 15 \mathrm{~W})$ combined with EC $\left(6 \mathrm{~mA} \mathrm{~cm}^{-2}\right)$, the degradation rate of MC-LR was up to $93 \%$, thus the residual concentration of MC-LR in the water was less than $1 \mu \mathrm{g}$ $\mathrm{L}^{-1}$ (the limits set by WHO). The removal efficiency of US-EC far superior to US alone. When combining 6 and $10 \mathrm{~mA} \mathrm{~cm}^{-2}$ of EC with US at the same conditions, the increase of removal efficiency in US-EC comparing to EC was insignificant. This phenomenon can be explained by higher corrosion of the electrodes. It can be speculated that higher currents combined with ultrasonic irradiation, enhances the corrosion rates of electrodes thus reducing their efficiency. The known cleaning effect of ultrasound due to the formation of liquid micro jets and shock waves generated by cavitation bubbles collapse can assist the initiated corrosion of electrodes at higher currents. Moreover, it was reported that ultrasound can both promote and suppress the corrosion of metals ${ }^{[21,22]}$. For that reason, the careful optimization of related parameters should be done for both EC, US and US-EC processes.

\section{Conclusion}

This study is the first reported work conducted US-EC on the degradation of MC-LR in water. The study revealed a synergetic effect of combined US and EC of MC-LR on mineralization efficiency. An applied current of $6 \mathrm{~mA} \mathrm{~cm}^{-2}$ was found to be the most applicable parameter for the electrolysis process in this study. The ultrasonic powers of $15 \mathrm{~W}$ at $20 \mathrm{kHz}$ frequency provide higher mineralization efficiency for MC-LR degradation. The degradation rate of MC-LR was up to 93\% applying US $(20 \mathrm{kHz}, 15 \mathrm{~W})$ to the $\mathrm{EC}(6 \mathrm{~mA} \mathrm{~cm}-2)$ for $5 \mathrm{~min}$, and the residual concentration of MCLR in the water was less than $1 \mu \mathrm{g} \mathrm{L}^{-1}$ (the limits set by WHO). With processing time is extended to 10 minutes, the degradation rate was reached $99 \%$.

\section{References}

[1]. Roegner A F, Brena B, Gonzalez-Sapienza G, et al. Microcystins in potable surface waters: toxic effects and removal strategies[J]. Journal Of Applied Toxicology. 2014, 34(5): 441-457.

[2]. Li Y, Chen J, Zhao Q, et al. A Cross-Sectional Investigation of Chronic Exposure to Microcystin in Relationship to Childhood Liver Damage in the Three Gorges Reservoir Region, China[J]. Environmental Health Perspectives. 2011, 119(10): 1483-1488. 
[3]. Le Manach S, Khenfech N, Huet H, et al. Gender-Specific Toxicological Effects of Chronic Exposure to Pure Microcystin-LR or Complex Microcystis aeruginosa Extracts on Adult Medaka Fish[J]. Environmental Science \& Technology. 2016, 50(15): 8324-8334.

[4]. Hu Y, Chen J, Fan H, et al. A review of neurotoxicity of microcystins[J]. Environmental Science And Pollution Research. 2016, 23(8): 7211-7219.

[5]. Chen L, Chen J, Zhang X, et al. A review of reproductive toxicity of microcystins[J]. Journal Of Hazardous Materials. 2016, 301: 381-399.

[6]. Svircev Z, Drobac D, Tokodi N, et al. Epidemiology of Cancers in Serbia and Possible Connection with Cyanobacterial Blooms[J]. Journal Of Environmental Science And Health Part C-Environmental Carcinogenesis \& Ecotoxicology Reviews. 2014, 32(4): 319-337.

[7]. Svircev Z, Drobac D, Tokodi N, et al. Epidemiology of Primary Liver Cancer in Serbia and Possible Connection With Cyanobacterial Blooms[J]. Journal Of Environmental Science And Health Part C-Environmental Carcinogenesis \& Ecotoxicology Reviews. 2013, 31(3): 181-200.

[8]. .Svircev Z, Krstic S, Miladinov-Mikov M, et al. Freshwater Cyanobacterial Blooms and Primary Liver Cancer Epidemiological Studies in Serbia[J]. Journal Of Environmental Science And Health Part C-Environmental Carcinogenesis \& Ecotoxicology Reviews. 2009, 27(PII 9085890681): 36-55.

[9]. Quality D. Cyanobacterial toxins : Microcystin-LR in Drinking-water Background document for development of WHO Guidelines for Drinking-water Quality[J]. 1998.

[10]. Xue Q, Su X, Steinman A D, et al. Accumulation of microcystins in a dominant Chironomid Larvae (Tanypus chinensis) of a large, shallow and eutrophic Chinese lake, Lake Taihu[J]. Scientific Reports. 2016, 6(31097).

[11]. Lahti K, Rapala J, Fardig M, et al. Persistence of cyanobacterial hepatotoxin, microcystin-LR in particulate material and dissolved in lake water[J]. Water Research. 1997, 31(5): 1005-1012.

[12]. Thokchom B, Pandit A B, Qiu P, et al. A review on sonoelectrochemical technology as an upcoming alternative for pollutant degradation[J]. Ultrasonics Sonochemistry. 2015, 27: 210-234.

[13]. Klima J. Application of ultrasound in electrochemistry. An overview of mechanisms and design of experimental arrangement[J]. Ultrasonics. 2011, 51(2): 202-209.

[14]. Huang Y, Zhou T, Wu X, et al. Efficient sonoelectrochemical decomposition of sulfamethoxazole adopting common Pt/graphite electrodes: The mechanism and favorable pathways[J]. Ultrasonics Sonochemistry. 2017, 38: 735-743.

[15]. Trujillo-Ortega A, Delgadillo S A M, Mendoza-Escamilla V X, et al. Modeling the Removal of Indigo Dye from Aqueous Media in a Sonoelectrochemical Flow Reactor[J]. International Journal Of Electrochemical Science. 2013, 8(3): 3876-3887.

[16]. Deseada Esclapez M, Tudela I, Isabel Diez-Garcia M, et al. Towards the complete dechlorination of chloroacetic acids in water by sonoelectrochemical methods: Effect of the cathode material on the degradation of trichloroacetic acid and its degradation by-products [J]. Applied Catalysis B-Environmental. 2015, 166: 66-74.

[17]. Bringas E, Saiz J, Ortiz I. Kinetics of ultrasound-enhanced electrochemical oxidation of diuron on boron-doped diamond electrodes [J]. Chemical Engineering Journal. 2011, 172(2-3): 1016-1022.

[18]. Guzman-Duque F L, Petrier C, Pulgarin C, et al. Synergistic Coupling Between Electrochemical and Ultrasound Treatments for Organic Pollutant Degradation as a Function of the Electrode Material (IrO2 and BDD) and the Ultrasonic frequency (20 and $800 \mathrm{kHz})[\mathrm{J}]$. International Journal Of Electrochemical Science. 2016, 11(9): 7380-7394.

[19]. Thokchom B, Kim K, Park J, et al. ultrasonically enhanced electrochemical oxidation of ibuprofen [J]. Ultrasonics Sonochemistry. 2015, 22: 429-436.

[20]. Son Y, Lim M, Ashokkumar M, et al. Geometric Optimization of Sonoreactors for the Enhancement of Sonochemical Activity [J]. Journal Of Physical Chemistry C. 2011, 115(10): 4096-4103.

[21]. Wang R, Nakasa K. Effect of ultrasonic wave on the growth of corrosion pits on SUS304 stainless steel [J]. Materials Transactions. 2007, 48(5): 1017-1022. 
[22]. Whillock G, Harvey B F. Ultrasonically enhanced corrosion of 304L stainless steel .2. The effect of frequency, acoustic power and horn to specimen distance[J]. Ultrasonics Sonochemistry. 1997, 4(1): 33-38. 